\title{
Glucocorticoid-Induced Avascular Bone Necrosis: Diagnosis and Management
}

\author{
K.L. Chan and C.C. Mok ${ }^{*}$ \\ Department of Medicine, Tuen Mun Hospital, Hong Kong, China
}

\begin{abstract}
Glucocorticoid use is one of the most important causes of avascular bone necrosis (AVN). The pathogenesis of glucocorticoid-induced AVN is not fully understood but postulated mechanisms include fat hypertrophy, fat emboli and intravascular coagulation that cause impedance of blood supply to the bones. Data regarding the relationship between AVN and dosage, route of administration and treatment duration of glucocorticoids are conflicting, with some studies demonstrating the cumulative dose of glucocorticoid being the most important determining factor. Early recognition of this complication is essential as the prognosis is affected by the stage of the disease. Currently, there is no consensus on whether universal screening of asymptomatic AVN should be performed for long-term glucocorticoid users. A high index of suspicion should be exhibited for bone and joint pain at typical sites. Magnetic resonance imaging (MRI) or bone scintigraphy is more sensitive than plain radiograph for diagnosing early-stage AVN. Conservative management of AVN includes rest and reduction of weight bearing. Minimization of glucocorticoid dose or a complete withdrawal of the drug should be considered if the underlying conditions allow. The efficacy of bisphosphonates in reducing the rate of collapse of femoral head in AVN is controversial. Surgical therapy of AVN includes core decompression, osteotomy, bone grafting and joint replacement. Recent advances in the treatment of AVN include the use of tantalum rod and the development of more wear resistant bearing surface in hip arthroplasty.
\end{abstract}

Keywords: Avascular, osteonecrosis, aseptic necrosis, corticosteroid, glucocorticoid.

\section{INTRODUCTION}

Avascular bone necrosis (AVN), also known as osteonecrosis, aseptic necrosis of bone, ischemic bone necrosis and osteochondritis desiccans, is a condition that causes significant morbidity and impairment of daily function to patients. AVN involves progressive destruction of bone as a result of compromise of bone vasculature, death of osteocytes and fat cells and alteration of bone architecture. The most common cause of AVN is trauma, which causes direct disruption of blood supply [1]. Non-traumatic causes or associations include the use of glucocorticoids [2], alcoholism [3,4], hematological diseases (sickle cell anemia, thalassemia, polycythemia, hemophilia, myeloproliferative disorder) [5,6], metabolic diseases (Gaucher disease), hypercholesterolemia [7], pregnancy, chronic renal failure, hyperparathyroidism, Cushing's disease, autoimmune diseases [8], chronic pancreatitis, caisson disease, radiation, congenital hip dislocation [9], and use of potent intravenous bisphosphonates (Table 1). Glucocorticoid use and alcoholism comprise $90 \%$ of all non-traumatic causes of AVN [10].

Glucocorticoid-induced AVN most commonly affects the femoral head [1], but it can occur in any skeletal sites such as the knee, shoulder, ankle and the hand [11]. The most common symptom is pain, which is usually insidious in

*Address correspondence to this author at the Department of Medicine, Tuen Mun Hospital, Tsing Chung Koon Road, New Territories, Hong Kong, SAR China; Tel: (852) 2468 5386; Fax: (852) 2456 9100;

E-mail: ccmok2005@yahoo.com
Table 1. Conditions Associated with Avascular Necrosis

\begin{tabular}{|l|}
\hline Trauma \\
\hline Iatrogenic \\
\hline -Use of glucocorticoids \\
-alcohol \\
-bisphosphonate use \\
\hline Hematological \\
\hline -sickle cell anemia \\
-thalassemia \\
-polycynthemia \\
-hemophilia \\
-myeloproliferative disorders \\
\hline Metabolic \\
\hline -Gaucher disease \\
-hypercholesterolemia \\
-pregnancy \\
-chronic renal failure \\
-Hyperparathyroidism \\
-Cushing's disease \\
\hline Autoimmune disease \\
\hline -systemic lupus erythematosus \\
-rheumatoid arthritis \\
\hline Gastrointestinal \\
\hline -Chronic pancreatitis \\
\hline Orthopaedics cause \\
\hline -congenital hip dislocation \\
\hline
\end{tabular}


onset, and exacerbated by activity and exercise. With time, the pain may occur at rest and affects function and range of motion of the involved joints. It is crucial for early identification of this condition, especially in susceptible individuals because treatment options for advanced disease are limited and many sufferers of glucocortoicoid-induced AVN are young and active individuals.

\section{EPIDEMIOLOGY OF GLUCOCORTIOID-INDUCED AVN}

Glucocorticoid-induced AVN causes significant morbidity and accounts for around $10 \%$ of all cases of total hip replacement in the United States [12]. The prevalence of glucocorticoid-induced AVN is between 3\% and 38\% [1], depending on the underlying diseases, glucocorticoid dosage and route of administration. Two medical conditions commonly associated with glucocortioid-induced AVN are post-renal transplantation and systemic lupus erythematosus (SLE). The incidence of renal transplant recipients receiving glucocorticoids is between $3 \%$ and $41 \%$ [13], while the incidence of AVN among glucocorticoid-treated SLE patients is $4 \%$ to $40 \%$ [1].

\section{PATHOGENESIS}

Up till now the mechanisms by which glucocortoicoid induces AVN are not fully understood. Hypotheses include fat cell hypertrophy, fat embolisation, intravascular coagulation and osteocyte apoptosis, with a similar final common pathway of compromise of vasculature of bone and bone marrow, leading to ischemic necrosis of the bony tissues and subsequent mechanical failure and finally collapse of the bone.

Fat cell hypertrophy and fat emboli were demonstrated in rabbits which were given high-dose cortisone [14]. These emboli caused obliteration of vasculature in the subchondral bone of femur and humeral heads. Increase in the number of marrow fat cells were also noted in these rabbits. Similar finding of fat cell hypertrophy was also demonstrated in pluripotent cell line obtained from mice bone marrow in vitro after dexamethasone was added [15]. It is postulated that fat cell hypertrophy would cause expansion of cell volume within a restricted volume of the femoral head, thus a decrease in blood perfusion and leads to AVN. On the other hand, fat emboli deposits within the subchondral vessels and sinusoids appear to activate the complement pathway and cause deposition of immune complex and subsequent activation of the thrombotic process such as intravascular coagulation, leading to AVN [16]. A role of the lipid lowering agents in the treatment of AVN has been demonstrated in animals $[17,18]$. When rabbits receiving corticosteroid treatment were given clofibrate, fat cell size was reduced and so was the intra-cortical pressure, leading to the improvement of blood flow [19]. However, the efficacy of the lipid lowering agents in the treatment and prevention of AVN in human is still unproven.

Recently glucocorticoid-induced osteocyte apoptosis has been suggested to be another pathogenetic mechanism of AVN [20, 21]. Apoptotic osteocytes were found in pathologic specimen of femoral head during total hip replacement in patients with glucocorticoid-induced AVN.
Similar findings were not reported in those with AVN due to trauma or alcohol related causes [22]. These apoptotic osteocytes gradually accumulate in the bone causing disruption of osteocyte-lacunar-canalicular system and vascular space and finally collapse of femoral head.

\section{DIAGNOSIS OF AVN}

Typical symptom in a patient with AVN is pain, which is usually insidious in onset and aggregates with activity and weight bearing. Conventional radiography is the most convenient and inexpensive first-line investigation for the diagnosis of AVN. Abnormal findings in AVN include 'crescent sign' representing subchondral collapse, cystic or sclerotic change in femoral head, abnormal contours of femoral head, collapse or secondary degenerative change. However, plain radiograph is not sensitive in detecting early AVN lesions.

Bone scintigraphy helps to pick up AVN at an earlier stage [23]. In early AVN, there is increased osteoblastic activity and blood flow in the bone which may be picked up by bone scan. In later stage of AVN, the necrotic center of the bone shows decreased radioisotope uptake but there is increased uptake in the surrounding subchondral bone adjacent to the necrotic segment. Bone scan has the advantage of detecting abnormalities at multiple sites. It can be considered when patient complains of pain at multiple bone and joint areas. However, bone scan is less specific for the diagnosis of AVN. Other limitation includes radiation dose, poor spatial resolution and unable to quantify the lesion for prognostic purpose [24].

MRI is the most sensitive modality in diagnosing AVN (Figs. 1, 2). The early detectable change in T1 image is a single density line that represents the separation of normal and osteonecrotic bone. In T2 image there may be another line seen within this line which represents the increased vascularity of granulation tissue [25]. MRI also allows quantification of the area and extent of AVN [26]. The drawback of MRI scan is cost if multiple sites are involved.

\section{STAGING OF AVN}

Numerous staging systems have been proposed for femoral head AVN. Proper staging is important to determine the prognosis and to decide for the optimal treatment. Ficat and Arlet [27] proposed a classification of four stages of AVN based on radiographic findings. In stage I, the radiograph is normal. In stage II, the femoral head contour is preserved but there are signs of bone remodeling such as cystic and osteosclerotic regions. In stage III, there is subchondral collapse or flattening of femoral head. In stage $\mathrm{IV}$, the joint space is narrowed and secondary degenerative change is shown in acetabulum. Later, Steinberg et al. [28] put forward a new classification system involving six stages which take into account the quantification of femoral head involvement in both early and late stages from plain radiograph, bone scintigraphy or MRI scan. The newer classification system developed by the Association Research Circulation Osseous (ARCO) consists of stage 0-4 [10] (Table 2). Stage 0 is the stage when all diagnostic studies normal, diagnosis by histology only. Stage I is the early stage in which osteonecrosis is evident in bone scintigraphy 

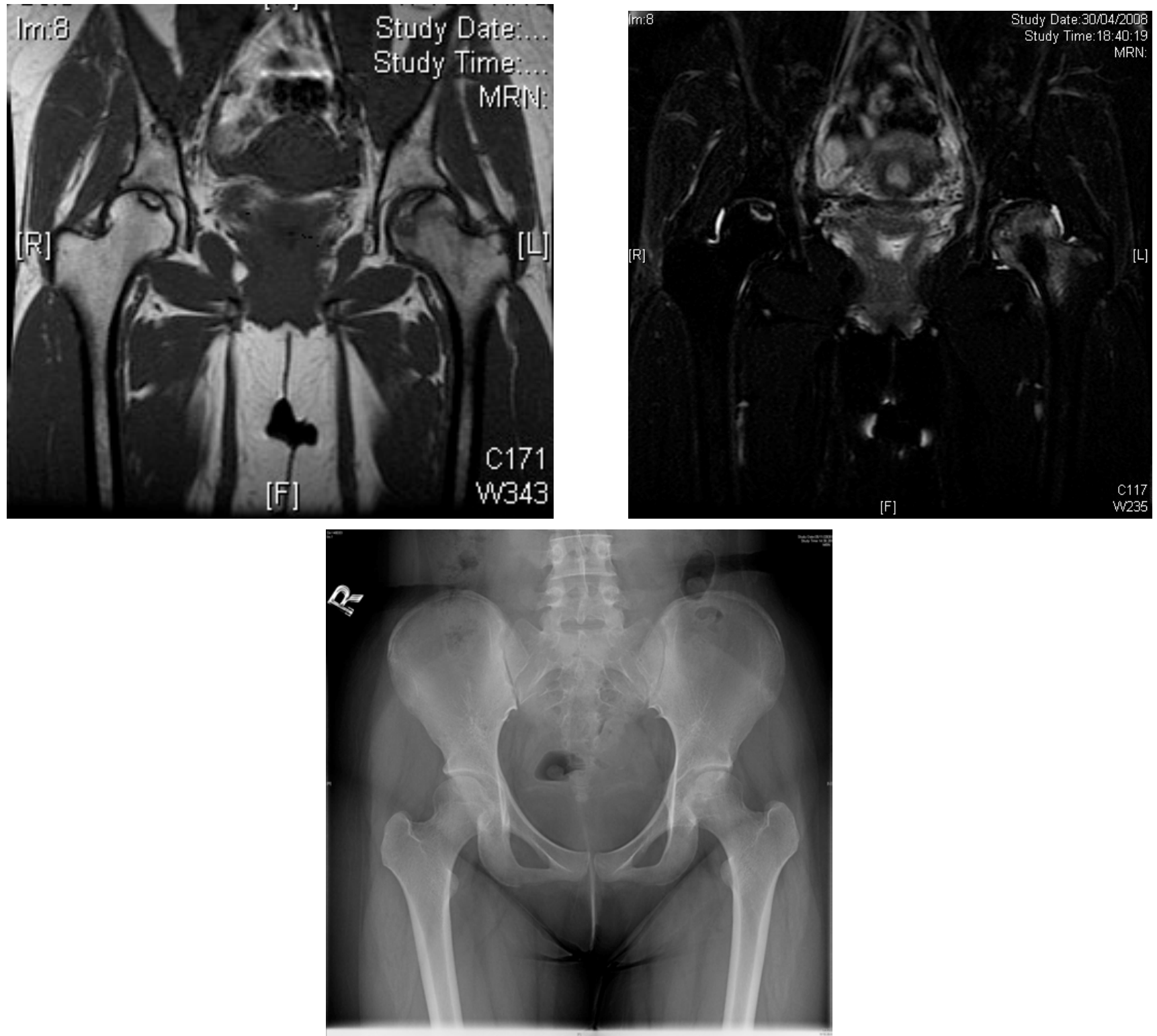

Fig. (1). AVN of the femoral heads in a 19-year-old woman with lupus nephritis treated with long-term glucocorticoid. (a) Coronal T1weighted MRI scan. (b) Coronal T2-weighted MRI scan. Heterogeneous area bordered by well defined T1W \& T2W hypointense rim was observed over the superior left femoral head. T1W \& $\mathrm{T} 2 \mathrm{~W}$ hyperintense lesions bordered by $\mathrm{T} 1 \mathrm{~W}$ hypointense $\mathrm{T} 2 \mathrm{~W}$ hyperintense rim was seen at superior right femoral head. Features are suggestive of bilateral AVN, more severe on the left side. (c) X-ray of the hips of the same patient - increased mixed sclerosis/lucency is seen at subchondral region of superior aspect of left femoral head, the configuration of which is still preserved (early AVN). The right hip appears unremarkable.

or MRI or both. X-ray finding is normal. Stage II is positive radiographic abnormalities (mottled appearance of the femoral head, osteosclerosis, cyst formation and osteopenia), but no sign of collapse in radiograph or CT scan. Stage III is the presence of crescent sign which signifies the subchrondral plate was separating from the necrotic cancellous bone which is apparent in both radiography and MRI scan. Stage IV is destruction of joint with secondary arthritic change.

\section{SITE OF INVOLVEMENT IN GLUCOCORTICOID- INDUCED AVN}

Glucocorticoid-induced AVN tends to occur at multiple sites, as illustrated by studies of SLE patients receiving long- term glucocorticoid treatment [29-31]. The reported proportion of SLE patients with AVN involving more than two joint areas varied from $70 \%$ to $90 \%$ in several case series [29-31]. In one report [29] evaluating 95 SLE patients with symptomatic AVN, the most commonly affected joints were hip and knee. Among these patients, 52 patients (54.7\%) had bilateral hip AVN while 18 patients $(18.9 \%)$ had bilateral knee AVN. Data from our group [8] showed that AVN occurred in 38 out of 320 SLE patients (12\%). The AVN patients had received a significantly higher mean daily dose of prednisolone $(15.6 \pm 2 \mathrm{mg}$ ) when compared to SLE controls who did not have AVN $(9.3 \pm 0.5 \mathrm{mg})$. The hip was the most common site of involvement (36 out of 38 patients, $95 \%$ ), and bilaterality occurred in $72 \%$ of patients. This is consistent with another prospective study [32] showing that 

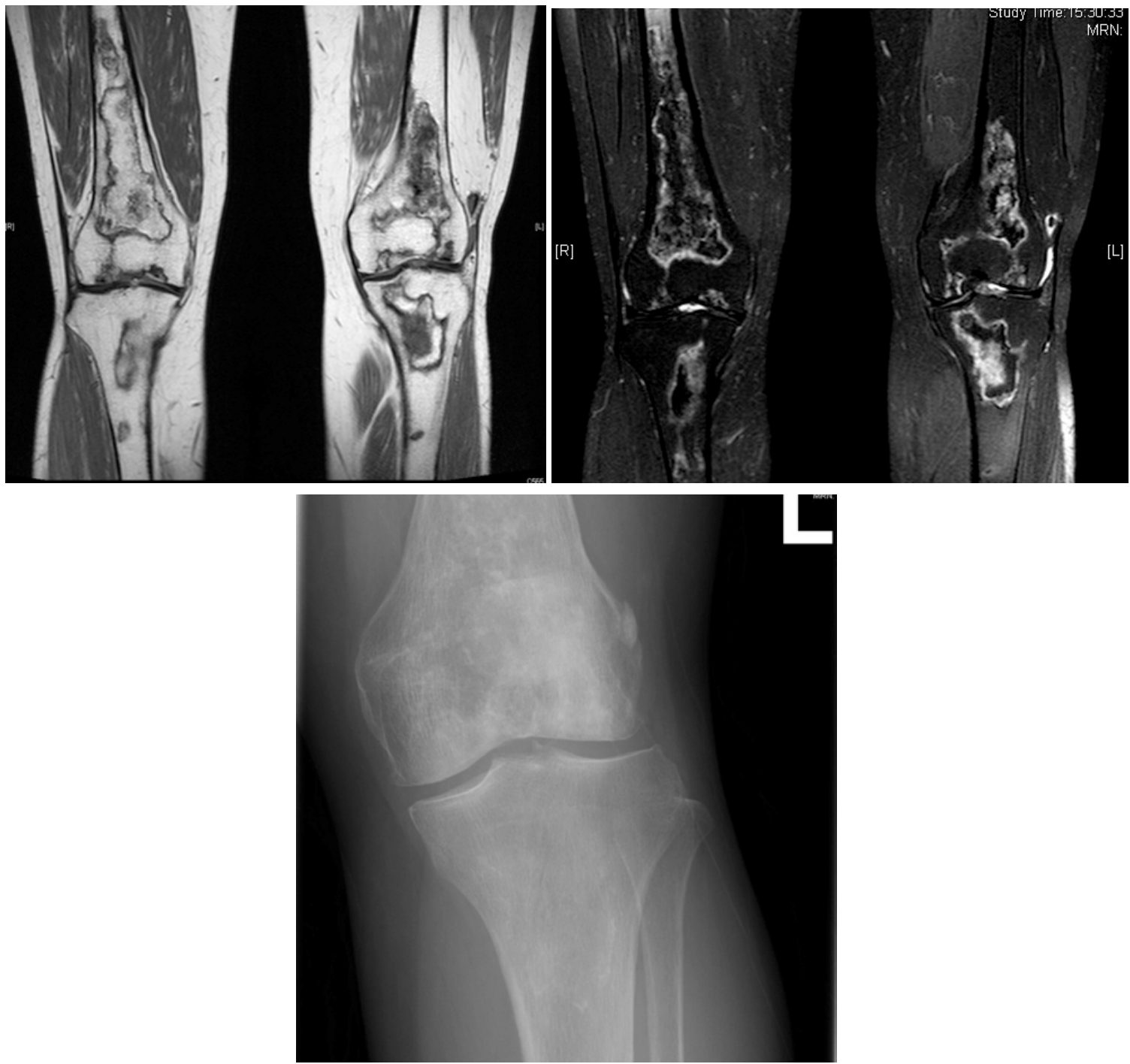

Fig. (2). AVN of both knees in a 53-year-old woman with SLE treated with glucocorticoid. (a) Coronal T1-weighted MRI scan. (b) Coronal T2-weighted MRI scan. Multifocal serpiginous areas are present around both knees, from distal femoral shaft to proximal tibial shaft. The areas have inner hypointense outer hyperintense rim on T2W sequences and enhancing outer rim. Similar lesion is also seen in left patella. Overall features are suggestive of AVN which also involves the subarticular region. (c) X-ray left knee of the same woman. Increased sclerosis is noted in subchondral region of lateral condyle, configuration of which is preserved. Serpigenous sclerosis is seen in medullary region of proximal tibia and distal femur, suggesting bone infarct.

in 120 patients with glucocorticoid-induced AVN, the most common site of involvement was hip (82\%) and knee (64\%), followed by shoulder $(20 \%)$ and ankle $(25 \%)$.

\section{ROUTE, CUMULATIVE DOSE, DURATION OF GLUCOCORTICOID TREATMENT AND AVN}

Data on the relationship between glucocorticoid dose, route of administration and duration of treatment leading to AVN are conflicting. Patients exposed to high-dose glucocorticoids with a longer treatment period were considered to be at higher risk of development of AVN [13, $33,34]$. On the other hand, there were reports demonstrating that AVN might develop over a short period of treatment with glucocorticoids [34-36]. Massardo et al. [35] reported that methylprednisolone pulse therapy was a risk factor for AVN. In their study, significantly more SLE patients who received pulse methylprednisolone (7 out of 36 SLE patients i.e. 19\%) had AVN compared with those without (10 of 154 patients [6\%], p<0.04). However, in another smaller study of 69 SLE patients by Migliaresi et al. [37], 17 patients received pulse steroid but none of them developed AVN. In addition to the oral and intravenous route of glucocorticoid administration, there were case reports of AVN which developed after intra-articular or intramuscular steroid injection $[38,39]$. The author attributed IMI or intra-articular steroid causing AVN because of the rapid occurrence after the administration.

In a review article summarizing 16 studies of AVN in patients with SLE [13], recent studies in the 1980s' or later demonstrated more evidence of an association between the mean daily dose and maximum daily dose with AVN in SLE patients [35, 40, 41]. In the retrospective study from Massardo et al. [35], it was reported that both daily dose of prednisolone of more than 40mg during the first month of treatment and pulse steroid were risk factors for AVN in 190 
SLE patients. Ono et al. [40] also showed that use of oral prednisolone $30 \mathrm{mg}$ for at least 1 month was an independent factor associated with AVN. Similarly, in post-renal transplant patients, recent studies generally showed positive correlation between mean daily glucocorticoid dose and AVN [42-45].

Table 2. Association Research Circulation Osseous (ARCO) Classification of Femoral Head Necrosis

\begin{tabular}{|c|l|}
\hline Stage & \\
\hline \hline 0 & All diagnostic studies normal, diagnosis by histology only \\
\hline 1 & $\begin{array}{l}\text { Plain radiographs and computed tomography normal, magnetic } \\
\text { resonance imaging positive and biopsy positive, extent of } \\
\text { involvement A, B, or C (less than 15 percent, 15 to 30 percent, } \\
\text { and greater than 30 percent, respectively). }\end{array}$ \\
\hline 2 & $\begin{array}{l}\text { Radiographs positive but no collapse, extent of involvement A, } \\
\text { B, or C }\end{array}$ \\
\hline 3 & $\begin{array}{l}\text { Early flattening of dome, crescent sign, computed tomography } \\
\text { or tomograms may be needed, extent of involvement A, B, or } \\
\text { C, further characterization by amount of depression (in } \\
\text { millimeter) }\end{array}$ \\
\hline 4 & $\begin{array}{l}\text { Flattening of femoral head with joint space narrowing, possible } \\
\text { other signs of early osteoarthritis }\end{array}$ \\
\hline
\end{tabular}

Studies also showed that cumulative dose of glucocorticoid may be a more important factor for AVN. Mok et al. [8] found that the cumulative dose of prednisolone at 1 and 4 months were higher in SLE patients who developed AVN compared to those did not (1.8g vs $1.1 \mathrm{~g}$ and $4.5 \mathrm{~g}$ vs $2.8 \mathrm{~g}$, respectively; $\mathrm{p}<0.01$ in both). This was supported by Sayarlioglu et al. [46] and Gladman et al. [47] who both showed a positive correlation between the cumulative prednisolone dose and AVN risk in SLE patients. In renal transplants patients, the risk of AVN were also related to the cumulative dose of prednisolone received $[45,48]$. Both Shibatani et al. and Saisu et al. demonstrated that there was a statistically significant correlation between the total glucocorticoid dose during first 2 months of renal transplant with femoral head AVN [45,48].

With respect to the time of onset of AVN after initiation of glucocorticoid, it can be developed as early as 1 year of glucocorticoid administration [49-52]. Koo et al. reported that 21 of 22 patients treated with glucocorticoid had MRI evidence of AVN of femoral head within 12 months of initiation of treatment [49]. Similarly, AVN of the hips and knees could be detected in $44 \%$ of SLE patients (32/72) by MRI after a mean of 3.1 months of high-dose glucocorticoid treatment [51]. Another prospective study [52] described that early MRI change of AVN of femoral head can be observed in mean of 3.6 months after initiation of glucocorticoid among 48 patients receiving highdose glucocorticoid. It is thus important to remain vigilance for the possibility of development AVN throughout the course of treatment, particularly during the first year of initiation of glucocorticoid therapy.

Regarding the progression of glucocorticoid-induced AVN, several studies suggested that a proportion of early AVN of hip and knee may undergo spontaneous regression. Spontaneous incomplete regression was seen in 7 out of 17 (41.1\%) patients with stage I glucocorticoid-induced AVN of knee without subsequent collapse using serial MRI scan [53]. Similarly, for hip AVN, a few studies have shown spontaneous improvement of necrotic area with follow up MRI [51, 52, 54]. Sakamoto et al. [52] showed that 14 of 31 hips $(45 \%)$ with early MRI evidence of AVN in glucocorticoid users underwent incomplete or complete regression on follow up. The regression was evident around 1 year after initiation of glucocorticoid, after which no addition improvement was noticed. Kopecky et al. [51] also demonstrated that 7 out of 25 AVN hips (28\%) among renal transplant patients regressed in size during follow up. One important factor identified to predict the spontaneous regression is the stage of AVN. Early stage AVN is more likely to regress. Another important predictor factor is the time between diagnosis initiation of glucocorticoid and diagnosis of AVN [53]. Regression is more likely to occur with AVN that were diagnosed early after initiation of glucocorticoid. Some of these patients with AVN regression were still on glucocorticoid, so discontinuation of glucocorticoid did not seem to affect the regression of AVN [53]. Size and location of lesion were not shown to affect the regression of AVN [53].

In summary, current evidence suggests that AVN may develop in patients receiving high dose glucocorticoid within a short period of time, or even after pulse therapy with big doses of glucocorticoids. MRI evidence of AVN may appear within 1 year of initiation of glucocorticoid. Early AVN lesions may undergo spontaneous regression.

\section{TREATMENT OF GLUCOCORTICOID-INDUCED AVN}

The management of AVN includes conservative nonsurgical and surgical approach. Indication for surgical and non-surgical approach depends on stage of disease, size of lesion, age and co-morbidity of patients. General speaking, the prognosis depends on staging of disease, so it is important to diagnosis AVN early so that prompt treatment can be initiated.

\section{GENERAL APPROACH}

In patients with glucocorticoid-induced $\mathrm{AVN}$ it is crucial to minimize the dosage and duration of glucocorticoid use. This could be achieved by addition or switching to a steroid sparing agent. In patients with more stable disease the use of oral glucocorticoid might be preferred to pulse high-dose therapy. It is also important to advise patients against other AVN risk factors such as alcohol use.

Conservative management of AVN includes bed rest and reduction of weight bearing with the use of crutches or canes. However it is generally believed that such conservative approach alone will not be sufficient to halt disease progression. In a prospective review of 36 patients with hip AVN [55], the rate of successful treatment outcome (as gauged by Harris Hip Scores) of surgical approach was $70 \%$ compared to $20 \%$ in conservative approach in Ficat stage I AVN.

\section{PHARMACOLOGICAL INTERVENTION}

Several studies have reported the efficacy of the bisphosphonates in the treatment of AVN. However, evidence is controversial. Bisphosphonates increase 
osteoclasts apoptosis and inhibit the resorptive action of the osteoclasts. On the other hand, they reduce apoptosis of osteoblasts and osteocytes, thus retarding bone turnover. Agarwala et al. [56] showed that alendronate treatment in hip AVN led to a significant improvement in pain and disability score, as well as a significant increase in standing and walking time, with the efficacy lasting up to 10 years. They also reported a decrease in marrow edema in most cases by MRI scan after 1 year's treatment. In this study, a total of 40 patients were recruited, with 4 patients (10\%) being glucocorticoid users. However there was no control group. A randomized controlled study by Lai et al. [57] demonstrated that patients with AVN of the hip treated with 25 weeks of alendronate had a significant lower rate of femoral head collapse (7\%) compared to a control group who did not receive alendronate or had received placebo treatment $(76 \%)$. Thirty-three percent of patients recruited in this study had a history of glucocorticoid use. However, a more recent randomized controlled study demonstrated a different result [58]. Fifty two patients with AVN (in 65 hips) were randomized to alendronate $70 \mathrm{mg} /$ week treatment or placebo for 104 weeks. AVN was induced by glucocorticoids in 4 of 26 patients $(15 \%)$ of the alendronate group and 8 of 26 patients (31\%) of the placebo group. No statistical difference in progression of AVN could be demonstrated by plain radiography and MRI between the two groups after 2 years. Four of 32 patients (13\%) in alendronate group underwent total hip arthroplasty (THA), whereas 5 of $33(15 \%)$ patients in placebo group underwent THA. The number of THA in placebo group (5 out of 33 patients) was low compared to previous studies, which might have contributed to the lack of difference between alendronate and placebo groups.

Currently, there is not enough evidence to recommend the routine use of bisphosphonate in patients with AVN. Further studies with a larger number of patients are needed to confirm the therapeutic efficacy of bisphosphonates.

Another non-operative treatment option of AVN is hyperbaric oxygen (HBO) [59, 60]. HBO improves the oxygenation of hypoxic tissue and reduces edema by increasing the concentration of dissolved oxygen and inducing vasoconstriction. This accounts for the early pain relief in patients receiving HBO. In a randomized controlled study of 20 patients with Ficat stage II femoral head AVN of all causes, patients who received 30 treatment sessions of HBO in 6 weeks had significant greater improvement in pain and range of movement. Substantial radiographic healing of AVN was observed in 7 of 9 hips with HBO [59]. One disadvantage of HBO is its high cost of treatment. More studies are needed to evaluate its use as a primary treatment or adjunctive therapy for AVN.

\section{SURGICAL TREATMENT OF AVN}

\section{Core Depression}

Core decompression works by reduction of intramedullary pressure inside the femoral head by making a drill hole, thus improving blood flow to bone. This procedure is mainly indicated in early stage AVN. Mont et al. [10] reviewed 24 reports that included 1206 hips which have undergone core decompression. Seven hundred and eleven out of the 1130 hips (63\%) showed no radiographic evidence of progression of disease in follow up X-ray. Mean duration of follow up was 30 months. Patients with earlier stage had better results, in which the average rate of survival was $84 \%$ for Ficat stage 1, 65\% for stage 2 and $47 \%$ for stage 3 . The authors concluded that core decompression is effective in delaying the need for total hip arthroplasty. The result was supported by another prospective study [55] which showed that the successful rate (as reflected by the Harris hip score) was higher with core decompression compared to conservative approach in both stage I, II and III hip. However, one smaller prospective study [61] showed that core decompression could provide pain relief but did not influence the time of collapse in patients with AVN.

\section{Osteotomy}

Osteotomy aims to relocate the necrotic area of bone from the weight loading area of acetabulum, so as to redistribute the weight loading to articular cartilage, which is supported by healthy bone. Results of studies of osteotomy vary according to different types of osteotomy. Transtrochanteric anterior rotational osteotomy has showed good results but was technically demanding [62]. Varus osteotomy aims to relocate the necrotic bone medially and shift the intact lateral articular surface into the weight bearing position. One study [63] showed that 28 of 32 hips (76\%) with Ficat stage II or III AVN had good and durable surgical results according to Harris hips-scoring system after corrective osteotomy for 11.5 years. The results were even better in those who had not received glucocorticoids $(85 \%$ achieved good excellent results). This operation, however, has several disadvantages that include elevation or lateral displacement of the greater trochanter.

\section{Bone Graft}

Bone graft aims to provide mechanical support to subchondral bone or cartilage. There are various types of bone grafting, some combined with osteotomy, osteochondral grafts, muscle pedicle bone grafts, and some are vascularized grafts to improve blood flow of the bone by achieving revascularization. Vascularized bone grafting is reported to have a higher successful rate than cortical graft, only $11 \%$ with stage II hips with free vascularized fibular grafting need to undergo total hip replacement in a 5 year follow up period [64]. In another study with longer follow up period of 10 years time, only $10.5 \%$ patients with vascularized graft had failed and required total hip replacement [65]. Possible morbidities after operation include weakness, sensory deficit and pain [66]. A study done in 1996 which looked into patients who underwent vascularized fibular grafts showed that at five years, $2.7 \%$ patients have lower limb motor weakness, $11 \%$ has sensory deficit and $8 \%$ has pain at sites other than ankle [67].

\section{Tantalum Rod}

The new tantalum rod is made up of a biocompatible material with a porosity of $75 \%$. It has been used to replace the necrotic bone segment to prevent collapse in Steinberg stage I-III femoral AVN. The presence of pores allows rapid bony ingrowth [68]. Recent studies showed encouraging results of this treatment modality [68-70]. Survivorship of the hip without the need to conversion to total hip arthroplasty was up to $70 \%$ at 6 years [68]. The disadvantage 
of the tantalum rod is that if the disease progresses, the tip of tantalum rod in the collapsed femoral head may protrude into the acetabulum. Moreover, there will be technical difficulty in removal of the tantalum rod in case of complications because of its strong bio-integration to the surrounding bone.

\section{Joint Replacement}

In the advanced stage of AVN, once the femoral head has collapsed or the destruction process has involved the acetabulum, joint replacement is indicated. These include femoral resurfacing arthroplasty, hemiarthroplasty, and total hip arthroplasty. Compared with total hip replacement due to other causes like osteoarthritis, patients with AVN in general have a less favorable long term durability or high failure rate [71], likely because the patients are of younger age and are functionally more active. There is a concern for the need of repeated revision of hip replacement in younger patients due to the wear and osteolysis of joint surface, thus the use of joint preserving procedures should be explored in younger patients whenever possible especially in early stage of AVN. Recent advances include the use of more wear resistant bearing surfaces. Highly cross-linked polyethylene was shown to have excellent results with decreased wear rate and lower incidence of osteolysis. One recent study showed that the annual penetration was below $0.01 \mathrm{~mm} /$ year during 7 year follow up in patients with primary total hip arthroplasties using highly cross-linked polyethylene (81 out of 113 hips with AVN) [71]. Another more wear resistant bearing surface is ceramic- on- ceramic which also showed satisfactory clinical and radiological results especially in active and young patients [72]. However, squeaking, which is a high pitch noise related to the movement of prosthetic joint, is a concern [73].

\section{CONCLUSION}

In conclusion, glucocorticoid use is one of the commonest and most important causes of non-traumatic AVN. Postulated pathogenetic mechanisms of glucocorticoid-induced AVN include fat hypertrophy, fat emboli and intravascular coagulation. MRI is the most sensitive modality in picking up early stage of AVN. In patients receiving glucocorticoids, AVN can develop as early as in the first 12 months. At present there is no consensus to recommend universal screening for asymptomatic AVN in long-term users of glucocorticoids. Physicians should have a high index of suspicion for persistent pain at typical sites after commencement of glucocorticoids. Judicious use of glucocorticoids, such as the use of lowest effective doses, avoiding prolonged courses, minimizing the use of intravenous pulse methylprednisolone and early institution of glucocorticoid sparing agents may help to decrease the risk of AVN. Conservative management includes bed rest, reduction of weight bearing with use of crutches or canes and pharmacological therapy. At present there is not enough evidence to support the routine use of bisphosphonates or hyperbaric oxygen in glucocorticoid-induced AVN. Surgical treatment of AVN includes core decompression, osteotomy, bone graft and tantalum rod that may help to delay the progression of AVN. Arthroplasty are indicated for advanced AVN and articular collapse. Durability is a concern as patients suffered from glucocorticoid- induced AVN are mostly young. More wear resistant hip prostheses are being developed.

\section{CONFLICT OF INTEREST}

The authors confirm that this article content has no conflicts of interest.

\section{ACKNOWLEDGEMENTS}

Declared none.

\section{REFERENCES}

[1] Assouline-Dayan Y, Chang C, Greenspan A, Shoenfeld Y, Gershwin ME. Pathogenesis and natural history of osteonecrosis. Semin Arthritis Rheum 2002; 32(2): 94-124

[2] Weinstein RS. Glucocorticoid-induced osteonecrosis. Endocrine 2012; 41(2): 183-90.

[3] Wang Y, Li Y, Mao K, Li J, Cui Q, Wang GY. Alcohol-induced adipogenesis in bone and marrow: a possible mechanism for osteonecrosis. Clin Orthop Relat Res 2003; 410: 213-24.

[4] Shigemura T, Nakamura J, Kishida S, et al. The incidence of alcohol-associated osteonecrosis of the knee is lower than the incidence of steroid-associated osteonecrosis of the knee: an MRI study. Rheumatology (Oxford) 2012; 51(4): 701-6.

[5] MacNicol MF, Ludlam CA. Does avascular necrosis cause collapse of the dome of the talus in severe hemophilia? Haemophilia 1999; 5(2): 139-42.

[6] Poignard A, Flouzat-Lachaniette CH, Amzallag J, Galacteros F, Hernigou P. The natural progression of symptomatic humeral head osteonecrosis in adults with sickle cell disease. J Bone Joint Surg Am 2012; 94(2): 156-62.

[7] Moskal JT, Topping RE, Franklin LL. Hypercholesterolemia: an association with osteonecrosis of the femoral head. Am J Orthop 1997; 26(9): 609-12.

[8] Mok CC, Lau CS, Wong RW. Risk factors for avascular bone necrosis in systemic lupus erythematosus. Br J Rheumatol 1998; 37(8): 895-900.

[9] Gregosiewicz A, Wosko I. Risk factors of avascular necrosis in the treatment of congenital dislocation of the hip. J Pediatr Orthop 1988; 8(1): 17-9.

[10] Michael AM, David H. Non-traumatic avascular necrosis of the femoral head. J Bone Joint Surg Am 1995; 77(3): 459-74.

[11] Kelman GJ, Williams GW, Colwell Jr CW. Steroid-related osteonecrosis of the knee. Two case reports and a literature review. Clin Orthop Relat Res 1990; 257: 171-6.

[12] Mankin HJ. Non traumatic necrosis of bone. N Engl J Med 1992; 326: 1473-9.

[13] Drescher W, Schlieper G, Floege J, Eitner F. Steroid-related osteonecrosis-an update. Nephrol Dial Transplant 2011; 26(9): 2728-31.

[14] Wang GJ, Sweet DE, Reger SI, Thompson RC. Fat-cell changes as a mechanism of avascular necrosis of the femoral head in cortisone-treated rabbits. J Bone Joint Surg Am 1977; 59: 729-35.

[15] Cui Q, Wang GJ, Balian G. Steroid induced adipogenesis in a pluripotential cell line from bone marrow. J Bone Joint Surg Am 1977; 59(6): 729-35.

[16] Jones JP Jr. Fat embolism and osteonecrosis. Orthop Clin North Am 1985; 16(4): 595-633.

[17] Wang GJ, Cui Q, Balian G. The pathogenesis and prevention of steroid-induced ostseonecrosis. Clin Orthop Relat Res 2000; 370: 295-310.

[18] Iwakiri K, Oda Y, Kaneshiro Y, et al. Effect of simvastatin on steroid inudced osteonecrosis evidenced by the seum lipid level and hepatic cytochrome P4503A in a rabbit model. J Orthop Sci 2008; 13(5): 463-8.

[19] Wang GJ, Rawles JG, Hubbard SL, Stamp WG. Steroid induced femoral head pressure changes and their response to lipid clearing agents. Clin Orthop 1983; 174: 298-302.

[20] Kabata T, Kubo T, Matsumoto T. Apoptotic cell death in steroid induced osteonecrosis: an experimental study in rabbits. J Rheumatol 2000; 27(9): 2166-71.

[21] Calder JD, Buttery L, Revell PA, Pearse M, Polak JM. Apoptosis-a significant cause of bone cell death in osteonecrosis of the femoral head. J Bone Joint Surg Br 2004; 86(8): 1209-13. 
[22] Weinstein RS, Nicholas RW, Manolagas SC. Apoptosis of osteocytes in glucocorticoid induced osteonecrosis of the hip. Endocrinology 2000; 85(8): 2907-12.

[23] Hayes CW, Balkissoon AR. Current concepts in imaging of the pelvis and hip.al. Orthop Clin North Am 1997; 28(4): 617-42.

[24] Malizos KN, Karantanas AH, Varitimidis SE, Dailiana ZH, Bargiotas K, Maris T. Osteonecrosis of the femoral head: etiology, imaging and treatment. Eur J Radiol 2007; 63(1): 16-28.

[25] Kokubo T, Takatori Y, Ninomiya S, Nakamura T, Kamogawa M. Magnetic resonance imaging and scintigraphy of avascular necrosis of the femoral head. Prediction of subsequent segmental collapse. Clin Orthop Relat Res 1992; 277: 54-60.

[26] Karantanas AH, Drakonaki EE. The role of MR imaging in avascular necrosis of the femoral head. Semin Musculoskelet Radiol 2011; 15(3): 281-300.

[27] Ficat RP. Idiopathic bone necrosis of femoral head. Early diagnosis and treatment. J Bone Joint Surg Br 1985; 67(1): 3-9.

[28] Steinberg ME, Hayken GD, Steinberg DR. A quantitative system for staging avascular necrosis. J Bone and Joint Surg 1995; 77(1): 34-41.

[29] Gladman DD, Chaudhry-Ahluwalia V, Ibanez D, Bogoch E, Urowitz MB. Outcome of symptomatic osteonecrosis in 95 patients with systemic lupus erythematosus. J Rheumatol 2001; 28(10): 2226-9.

[30] Oh SN, Jee WH, Cho SM, et al. Osteonecrosis in patients with systemic lupus erythematosus: MR imaging and scintigraphic evaluation. Clin Imaging 2004; 28(4): 305-9.

[31] Collaborative Osteonecrosis Group. Symptomatic multifocal osteonecrosis. A multicenter study. Clin Orthop Relat Res 1999; 369: 312-26.

[32] Sakamoto M. A prospective study of steroid-induced osteonecrosis by MRI screening. Nippon Seikeigeka Gakkai Zasshi 1994; 68(5): 367-78.

[33] McAvoy S, Baker KS, Mulrooney D, Blaes A, Arora M, Burns LJ. Corticosteroid dose as a risk factor for avascular necrosis of the bone after hematopoietic cell transplantation. Biol Blood Marrow Transplant 2010; 16(9): 1231-6.

[34] Yildiz N, Ardic F, Deniz S. Very early onset of steroid-induced avascular necrosis of the hip and knee in a patient with idiopathic thrombocytopenic purpura. Intern Med 2008; 44(22): 1989-92.

[35] Massardo L, Jacobelli S, Leissner M, González M, Villarroel L, Rivero S. High dose intravenous methylprednisolone therap associated with osteonecrosis in patients with systemic lupus erythematosus. Lupus 1992; 1(6): 401-5.

[36] Nagasawa K, Tada Y, Koarada S, et al. Very early development of steroid-associated osteonecrosis of femoral head in systemic lupus erythematosus: prospective study by MRI. Lupus 2005; 14(5): 38590.

[37] Migliaresi S, Picillo U, Ambrosone L, Di Palma G, Mallozzi M, Tesone ER. Avascular osteonecrosis in patients with SLE: relation to corticosteroid therapy and anticardiolipin antibodies. Lupus 1994; 3(1): 37-41.

[38] Laroche M, Arlet J, Mazieres B. Osteonecrosis of the femoral and humeral heads after intraarticular corticosteroid injections. J Rheumatol 1990; 17(4): 549-51.

[39] Yamamoto T, Schneider R, Iwamoto Y, Bullough PG. Rapid destruction of the femoral head after a single intraarticular injection of corticosteroid into the hip joint. J Rheumatol 2006; 33(8): 17014.

[40] Ono K, Tohjima T, Komazawa T. Risk factors of avascular necrosis of the femoral head in patients with systemic lupus erythematosus under high-dose corticosteroid therapy. Clin Orthop Relat Res 1992; 277: 89-97.

[41] Felson DT, Anderson JJ. Across-study evaluation of association between steroid dose and bolus steroids and avascular necrosis of bone. Lancet 1987; 1(8538): 902-6.

[42] Tang S, Chan TM, Lui SL, Li FK, Lo WK, Lai KN. Risk factors for avascular bone necrosis after renal transplantation. Transplant Proc 2000; 32(7): 1873-5.

[43] Celik A, Tekis D, Saglam F, Tunali S, Kabakci N, Ozaksoy D. Association of corticosteroids and factor $\mathrm{V}$, prothrombin, and MTHFR gene mutations with avascular osteonecrosis in renal allograft recipients. Transplant Proc 2006; 38(2): 512-6.

[44] Hedri H, Cherif M, Zouaghi K, et al. Avascular osteonecrosis after renal transplantation. Transplant Proc 2007; 39(4): 1036-8.
[45] Shibatani M, Fujioka M, Arai Y, et al. Degree of corticosteroid treatment within the first 2 months of renal transplantation has a strong influence on the incidence of osteonecrosis of the femoral head. Acta Orthop 2008; 79(5): 631-6.

[46] Sayarlioglu M, Yuzbasioglu N, Inanc M, et al. Risk factors for avascular bone necrosis in patients with systemic lupus erythematosus. Rheumatol Int 2012; 32(1): 177-82.

[47] Gladman DD, Urowitz MB, Chaudhry-Ahluwalia V, Hallet DC, Cook RJ. Predictive factors for symptomatic osteonecrosis in patients with systemic lupus erythematosus. J Rheumatol 2001; 28(4): 761-5.

[48] Saisu T, Sakamoto K, Yamada K, Kashiwabara H, Yokoyama T, Iida S. High incidence of osteonecrosis of femoral head in patients receiving more than $2 \mathrm{~g}$ of intravenous methylprednisolone after renal transplantation. Transplant Proc 1996; 28(3): 1559-60.

[49] Koo KH, Kim R, Ko GH, Song HR, Jeong ST, Cho SH. Preventing collapse in early osteonecrosis of the femoral head. A randomised clinical trial of core decompression. J Bone Joint Surg Br 1995; 77(6): 870

[50] Kopecky KK, Braunstein EM, Brandt KD, et al. Apparent avascular necrosis of the hip: appearance and spontaneous resolution of MR findings in renal allograft recipients. Radiology 1991; 179(2): 523-7.

[51] Oinuma K, Harada Y, Nawata Y, Takabayashi K, Abe I, Kamikawa K. Ostenecrosis in patients with systemic lupus erythematosus develops very early after starting high dose corticosteroid treatment. Ann Rheum Dis 2001; 60(12): 1145-8.

[52] Sakamoto M, Shimizu K, Iida S, Akita T, Moriya H, Nawata Y. Osteonecrosis of the femoral head: a prospective study with MRI. J Bone Joint Surg Br 1997; 79(2): 213-9.

[53] Takao M, Sugano N, Nishii T, Miki H, Yoshikawa H. Spontaneous regression of steroid-related osteonecrosis of the knee. Clin Orthop Relat Res 2006; 452: 210-5.

[54] Sakai T, Sugano N, Ohzono K, Matsui M, Hiroshima K, Ochi T. MRI evaluation of steroid- or alcohol-related osteonecrosis of the femoral condyle. Acta Orthop Scand 1998; 69(6): 598-602.

[55] Stulberg BN, Davis AW, Bauer TW, Levine M, Easley K. Osteonecrosis of the femoral head. A prospective randomized treatment protocol. Clin Orthop Relat Res 1991; 268: 140-51.

[56] Agarwala S, Shah SB. Ten-year follow up of avascular necrosis of femoral head treated with alendronate for 3 years. J Arthroplasty 2011; 26(7): 1128-34.

[57] Lai KA, Shen WJ, Yang CY, Shao CJ, Hsu JT, Lin RM. The use of alendronate to prevent early collapse of the femoral head in patients with nontraumatic osteonecrosis. J Bone Joint Surg Am 2005; 87(10): 2155-9.

[58] Chen CH, Chang JK, Lai KA, Hou SM, Chang CH, Wang GJ. Alendronate in the prevention of collapse of the femoral head in nontraumatic osteonecrosis: A two-year multicenter, prospective, randomized, double-blind, placebo-controlled study. Arthritis Rheum 2012; 64(5): 1572-8.

[59] Camporesi EM, Vezzani G, Bosco G, Mangar D, Bernasek TL. Hyperbaric oxygen therapy in femoral head necrosis. J Arthroplasty 2010; 25(6): 118-23.

[60] Reis ND, Schwartz O, Militianu D, et al. Hyperbaric oxygen therapy as a treatment for stage-I avascular necrosis of the femoral head. J Bone Joint Surg Br 2003; 85(3): 371-5.

[61] Koo KH, Kim R, Kim YS, et al. Risk period for developing osteonecrosis of the femoral head in patients on steroid treatment. Clin Rheumatol 2002; 21(4): 299-303.

[62] Atsumi T, Kajiwara T, Hiranuma Y, Tamaoki S, Asakura Y. Posterior rotational osteotomy for nontraumatic osteonecrosis with extensive collapsed lesions in young patients. J Bone Joint Surg 2006; 88-A(Suppl): $42-7$.

[63] Mont MA, Fairbank AC, Krackow KA, Hungerford DS. Corrective osteotomy for osteonecrosis of the femoral head. J Bone Joint Surg Am 1996; 78(7): 1032-8.

[64] Urbaniak JR, Coogan PG, Gunneson EB, Nunley JA. Treatment of osteonecrosis of the femoral head with free vascularized fibular grafting. A long-term follow-up study of one hundred and three hips. J Bone Joint Surg Am 1995; 77(5): 681-94.

[65] Yoo MC, Kim KI, Hahn CS, Parvizi J. Long-term followup of vascularized fibular grafting for femoral head necrosis. Clin Orthop Relat Res 2008; 466(5): 1133-40. 
[66] Assouline-Dayan Y, Chang C, Greenspan A, Shoenfeld Y, Gershwin ME. Pathogenesis and natural history of osteonecrosis. Semin Arthritis Rheum 2002; 32(2): 94-124.

[67] Vail TP, Urbaniak JR. Donor-site morbidity with use of vascularised autogenous fibular grafts. J Bone Surg Am 1996; 78(2): 204-11

[68] Varitimidis SE, Dimitroulias AP, Karachalios TS, Dailiana ZH, Malizos KN. Outcome after tantalum rod implantation for treatment of femoral head osteonecrosis: 26 hips followed for an average of 3 years. Acta Orthop 2009; 80(1): 20-5.

[69] Shuler MS, Rooks MD, Roberson JR. Porous tantalum implant in early osteonecrosis of the hip: preliminary report on operative, survival, and outcomes results. J Arthroplasty 2007; 22(1): 26-31.
[70] Saito S, Saito M, Nishina T, Ohzono K, Ono K. Long term results of total hip arthroplasty for osteonecrosis of the femoral head. A comparison with osteoarthritis. Clin Orthop 1989; 244: 198-207.

[71] Lee JH, Lee BW, Lee BJ, Kim SY. Midterm results of primary total hip arthroplasty using high cross-linked polyethylene: minimum 7 year follow-up study. J Arthroplasty 2011; 26(7): 1014-9.

[72] Byun JW, Yoon TR, Park KS, Seon JK. Third generation ceramicon-ceramic total hip arthroplasty in patients younger than 30 years with osteonecrosis of femora head. J Arthroplasty 2012; 27(7): 1337-43.

[73] Baek Sh, Kim SY. Cementless total hip arthroplasty with alumina bearings in patients younger than fifty with femoral head osteonecrosis. J Bone Joint Surg Am 2008; 90(6): 1314-20.

(c) Chan and Mok; Licensee Bentham Open.

This is an open access article licensed under the terms of the Creative Commons Attribution Non-Commercial License (http://creativecommons.org/licenses/by-nc/3.0/) which permits unrestricted, non-commercial use, distribution and reproduction in any medium, provided the work is properly cited. 